\title{
HUBUNGAN ANTARA INDEKS MASSA TUBUH DENGAN JENIS HERNIA INGUINALIS
}

\author{
Ringgo Alfarisi ${ }^{1 *}$, Mizar Erianto ${ }^{2}$, Fitri Chintiyani ${ }^{3}$ \\ ${ }^{1}$ Departemen Fisiologi Fakultas Kedokteran Universitas Malahayati \\ ${ }^{2}$ Departemen Ilmu Bedah Rumah Sakit Pertamina Bintang Amin \\ 3 Program Studi Kedokteran Fakultas Kedokteran Universitas Malahayati \\ Email Korespondensi: ringgo_alfarisi@yahoo.co.id \\ Disubmit: 22 Desember 2021 Diterima: 31 Desember 2021 Diterbitkan: 01 Januari 2022 \\ DOI: https://doi.org/10.33024/mnj.v1i1.5669
}

\section{ABSTRACT: RELATIONSHIP BETWEEN BODY MASS INDEX AND TYPES OF INGUINAL HERNIA}

Background: One of the risk factors that can influence or increase the incidence of inguinal hernia is overweight and obesity. Body mass index (BMI) is a simple way to see the nutritional status of adults, especially with regard to underweight and overweight.

Objective: To determine the relationship between Body Mass Index and the type of inguinal hernia

Research Methods: The design in this study used a cross sectional design. The population in this study were all inguinal hernia patients at Pertamina Bintang Amin Hospital Bandar Lampung in 2019-2020. The sample in this study amounted to 98 people using purposive sampling technique. Where patients with congenital hernia, chronic cough, and comorbid disease, were excluded from the study. The data obtained were analyzed using the chi square statistical test. Result: 18 respondents (20.45\%) patients diagnosed with lateral inguinal hernia had normal weight and 70 respondents (79.55\%) other respondents diagnosed with lateral inguinal hernia. Meanwhile, 6 respondents (60\%) who were diagnosed with medial inguinal hernia were overweight-obese, while the other 4 respondents (40\%) who were diagnosed with medial inguinal hernia were overweight-obese. The results of the bivariate statistical test using chi square obtained a p-value of 0.013 .

Conclusion: There is a significant relationship between body mass index and the type of inguinal hernia.

Keywords: Body Mass Index, Lateral Inguinal Hernia, Medial Inguinal Hernia

\section{INTISARI: HUBUNGAN ANTARA INDEKS MASSA TUBUH DENGAN JENIS HERNIA INGUINALIS}

Latar Belakang: Salah satu faktor resiko yang dapat mempengaruhi atau meningkatkan angka kejadian dari hernia inguinal adalah overweight dan obesitas. Indeks massa tubuh (IMT) merupakan cara sederhana untuk melihat status gizi orang dewasa, khususnya yang berkaitan dengan kekurangan dan kelebihan berat badan.

Tujuan: Untuk mengetahui hubungan antara Indeks Massa Tubuh dengan jenis hernia inguinalis 
Metode Penelitian: Rancangan dalam penelitian ini menggunakan desain cross sectional. Populasi dalam penelitian ini adalah seluruh pasien hernia inguinalis sebanyak di RS Pertamina Bintang Amin Bandar Lampung tahun 2019-2020. Sampel pada penelitian ini berjumlah 98 orang dengan menggunakan tekhnik purposive sampling. Dimana pasien dengan hernia kongenital, batuk kronis, dan penyakit komorbid, diekslusi dari penelitian. Data yang diperoleh dianalisa menggunakan uji statistic chi square.

Hasil penelitian: Didapatkan 18 responden (20,45\%) pasien yang didiagnosa hernia inguinalis lateralis memiliki berat badan normal dan 70 responden $(79,55 \%)$ responden lainnya yang didiagnosa hernia inguinalis lateralis. Sementara itu, 6 responden $(60 \%)$ responden yang didiagnosa hernia inguinalis medialis memiliki berat badan overweight-obesitas sedangkan 4 responden lainnya (40\%) yang didiagnosa hernia inguinalis medialis memiliki berat badan overweight-obesitas. Hasil uji statistik bivariat menggunakan chi square diperoleh nilai $\mathrm{p}$-value 0,013 .

Kesimpulan: Terdapat hubungan yang bermakna antara indeks massa tubuh dengan jenis hernia inguinalis.

Kata kunci: Indeks Massa Tubuh, Hernia Ingunalis Lateralis, Hernia Inguinalis Medialis

\section{PENDAHULUAN}

Hernia inguinalis merupakan kasus bedah digestif terbanyak setelah apendisitis. Hernia merupakan penonjolan isi suatu rongga melalui defek atau bagian lemah dari dinding rongga yang bersangkutan. Hernia terdiri atas cincin, kantong dan isi hernia. Menurut sifatnya, hernia terbagi menjadi hernia reponibel, irreponebel, obstruktif, dan strangulata (Amanulloh, 2016).

Satu-satunya terapi dari hernia inguinalis adalah operasi dan merupakan prosedur operasi yang paling banyak dilakukan di dunia (Rezky, dkk., 2019). Sepanjang tahun 2005 - 2010, World Health Organization (WHO) mengatakan terdapat 19.173.279 orang yang mengalami hernia (Gunawan, 2020). Insiden hernia menduduki peringkat ke lima besar yang terjadi di Amerika Serikat pada tahun 2007 sekitar 700.000 operasi hernia yang dilakukan tiap tahunnya. Angka kejadian hernia inguinalis lateralis di Amerika dapat di mungkinkan dapat terjadi karena anomali kongenital. Berbagai faktor penyebab berperan pada pembentukan pintu masuk hernia pada annulus internus yang cukup lebar sehingga dapat dilalui oleh kantong isi hernia. Hernia sisi kanan lebih sering terjadi dari pada di sisi kiri (Siti, dkk., 2016). Sementara itu, data Kementerian Kesehatan Republik Indonesia menunjukkan berdasarkan kelompok penyakit sistem pencernaan, hernia berada pada urutan ke-8 dengan 18,145 kasus, yang mana 273 diantaranya mengalami kematian. Dari keseluruhan tersebut, 15.051 kasus muncul pada laki-laki dan 3.094 kasus pada perempuan (Gunawan, 2020).

Secara umum, kejadian hernia inguinalis lebih banyak diderita oleh laki-laki daripada perempuan. Angka perbandingan kejadian hernia inguinalis 13,9\% pada laki-laki dan 2,1\% pada perempuan (Rezky, dkk., 2019). Perbandingan pria dengan wanita pada hernia indirect adalah 7:1. Angka kejadian hernia inguinalis 10 kali lebih banyak daripada hernia femoralis dan keduannya 
mempunyai persentase sekitar 75 $80 \%$ dari seluruh jenis hernia, hernia insisional $10 \%$, hernia ventralis $10 \%$, hernia umbilikalis $3 \%$, dan hernia lainnya sekitar 3\% (Lavelle, et al., 2002).

Salah satu faktor resiko yang
dapat mempengaruhi atau
meningkatkan angka kejadian dari hernia inguinal adalah overweight dan obesitas. Indeks massa tubuh (IMT) merupakan cara sederhana untuk melihat status gizi orang dewasa, khususnya yang berkaitan dengan kekurangan dan kelebihan berat badan. Indeks massa tubuh ini didapatkan dengan membagi berat badan (dalam kilogram) dengan kuadrat dari tinggi badan (dalam meter). Indeks massa tubuh diklasifikasikan menjadi underweight, normal, overweight dan obesitas. Dikatakan overweight jika kelebihan berat badan pada laki-laki dengan IMT $23-27 \mathrm{~kg} / \mathrm{m} 2$ dan perempuan 25- $27 \mathrm{~kg} / \mathrm{m} 2$, sedangkan obesitas diklasifikasikan sama pada laki-laki dan perempuan dengan IMT > 27 kg/m2 (Kato, 2017).

Secara keseluruhan 700 juta penduduk di dunia mengalami obesitas dan 2,3 miliar penduduk mengalami overweight (Kato, dkk., 2017). Berdasarkan Profil Kesehatan Indonesia tahun 2013, prevalensi status gizi berdasarkan Indeks Massa Tubuh untuk penduduk dewasa $(>18$ tahun) di Indonesia tahun 2013 adalah 8,7\% kategori kurus, 13,5\% berat badan lebih, dan obesitas 15,4\% (Kemenkes RI, 2015). Menurut Rosetto (2010) dan Park (2011), insiden hernia hernia inguinalis lebih tinggi pada pasien overweight dan obesitas dibandingkan dengan berat badan normal, hal yang sama juga di kemukakan oleh Pluta pada tahun 2011 dan Burney pada tahun 2016 (Rossetto, dkk., 2010; Park, dkk., 2011; Pluta, dkk., 2011).

Studi yang di lakukan Ruhl dkk pada tahun 2007 mengatakan bahwa insiden hernia inguinalis lebih rendah pada overweight dan obesitas dibandingkan dengan berat badan normal, pada studi yang di lakukan di RSUD Dr. M. Haulussy Ambon pada Tahun 2019 (Rezky, dkk., 2019). Selain itu, pada penelitian laainnya juga menyatakan bahwa hubungan IMT dan hernia inguinalis tidak jelas (Dario, dkk., 2016). Penelitian yang dilakukan oleh Ghayth, Waseem Kamel (2016) menyatakan bahwa IMT tidak secara langsung atau secara statistik memiliki hubungan sebagai faktor resiko hernia inguinalis (Ghayth, dkk., 2016).

\section{METODE PENELITIAN}

Jenis penelitian yang digunakan pada penelitian ini adalah menggunakan metode analitik observasional dengan pendekatan studi cross sectional. Penelitian ini dilakukan untuk mengetahui hubungan antara indeks massa tubuh dengan kejadian hernia ingunalis dengan menggunakan data sekunder yang didapatkan dari observasi rekam medis. Penelitian ini akan dilaksanakan pada bulan Desember 2020 - Januari 2021 di RS Pertamina Bintang Amin Bandar Lampung. Rancangan dalam penelitian ini menggunakan desain cross sectional yaitu desain penelitian yang bertujuan untuk melakukan observasi variabel yang dilakukan secara bersamaan. Populasi dalam penelitian ini adalah seluruh pasien hernia inguinalis sebanyak di RS Pertamina Bintang Amin Bandar Lampung tahun 2019-2020. Sampel pada penelitian ini berjumlah 98 orang dengan menggunakan tekhnik purposive sampling. Dimana pasien dengan hernia kongenital, batuk kronis, dan penyakit komorbid, diekslusi dari penelitian. Analisis data menggunakan uji statistic chis quare. 
HASIL PENELITIAN

\section{Karakteristik Responden}

Tabel 1. Distribusi Karakteristik Responden Penelitian

\begin{tabular}{ccc}
\hline Variabel & Jumlah & Presentase \\
\hline Jenis Kelamin & 2 & \\
- Perempuan & 96 & 2,0 \\
• Laki-Laki & & 98,0 \\
Usia & 16 & \\
- Remaja (12-25 tahun) & 24 & 16,3 \\
- Dewasa (26-45 tahun) & 58 & 24,5 \\
- Lansia (46-65 tahun) & 59,2 \\
\hline
\end{tabular}

Berdasarkan tabel 1., didapatkan distribusi frekuensi jenis kelamin pada pasien hernia inguinalis di RS Pertamina Bintang Amin mayoritas berjenis kelamin laki-laki (98\%). Selain itu, didapatkan pula bahwa mayoritas usia pada pasien hernia inguinalis di RS Pertamina Bintang Amin adalah berusia lansia $(59,2 \%)$.

\section{Analisis Univariat}

Tabel 2. Distribusi Variabel Penelitian

\begin{tabular}{|c|c|c|}
\hline Variabel & Jumlah & Presentase \\
\hline \multicolumn{3}{|l|}{ IMT } \\
\hline $\begin{array}{l}\text { - Normoweight (IMT 18,5- } \\
\left.24,9 \mathrm{Kg} / \mathrm{m}^{2}\right)\end{array}$ & 24 & 24,5 \\
\hline $\begin{array}{l}\text { - Overweight to Obese (IMT } \\
>24,9 \mathrm{Kg} / \mathrm{m}^{2} \text { ) }\end{array}$ & 74 & 75,5 \\
\hline \multicolumn{3}{|l|}{ Jenis Hernia Inguinalis } \\
\hline - Hernia Inguinalis Lateralis & 88 & 89,8 \\
\hline - Hernia Ingunalis Medialis & 10 & 10,2 \\
\hline
\end{tabular}

Hasil penelitian menunjukkan bahwa 24 responden $(24,5 \%)$ memiliki berat badan normal dan 74 responden lainnya $(75,5 \%)$ memiliki berat badan overweight-obesitas. Selain itu, didapatkan 88 responden $(89,80 \%)$ didiagnosa hernia inguinalis lateralis dan 10 responden $(10,20 \%)$ responden didiagnosa hernia inguinalis medialis.

\section{Analisis Bivariat}

Tabel 2. Hasil Uji Bivariat Hubungan Indeks Massa Tubuh dengan Jenis Hernia 
Inguinalis

\begin{tabular}{|c|c|c|c|c|c|c|}
\hline \multirow[b]{2}{*}{ IMT } & \multicolumn{2}{|c|}{ HIL } & \multicolumn{2}{|c|}{$\mathrm{HIM}$} & Total & \multirow{2}{*}{ P-Value } \\
\hline & $\mathrm{N}$ & $(\%)$ & $\mathrm{N}$ & $(\%)$ & $N \overline{(\%)}$ & \\
\hline Berat Badan Normal & 18 & 20,45 & 6 & 60 & 2424,50 & \\
\hline $\begin{array}{l}\text { Berat badan } \\
\text { overweight-obesitas } \\
\text { (>25,9 } \mathrm{Kg} / \mathrm{m} 2)\end{array}$ & 70 & 79,55 & 4 & 40 & 7475,50 & 0,013 \\
\hline Total & 88 & 100 & 10 & 100 & 98100 & \\
\hline
\end{tabular}

Berdasarkan data tabel 2. di atas, dapat diketahui bahwasannya hasil uji bivariat antara indeks massa tubuh dengan klasifikasi hernia inguinalis pada pasien hernia inguinalis di RS Pertamina Bintang Amin Bandar Lampung didapatkan 18 responden $(20,45 \%)$ pasien yang didiagnosa hernia inguinalis lateralis memiliki berat badan normal dan 70 responden $(79,55 \%)$ responden lainnya yang didiagnosa hernia

\section{PEMBAHASAN}

Hernia inguinalis terjadi karena menonjolnya sebagian isi perut (usus halus, omentum) melalui defek atau bagian lemah dinding perut. Faktor yang berperan adalah ada prosesus vaginalis yang terbuka, peningkatan tekanan intra abdomen dan kelemahan otot dinding perut karena bertambahnya usia (Sjamsuhidajat, 2017). Risiko terjadinya hernia inguinalis pada seseorang di karenakan oleh beberapa keadaan yang dapat menimbulkan peningkatan tekanan intra abdomen dan juga keadaan patologis pada struktur yang terkait (Sjamsuhidajat, 2017). Obesitas atau kelebihan berat badan secara alami akan memiliki tekanan internal yang lebih besar. Tekanan internal tersebut dengan mudah dapat mendorong jaringan lemak dan organ internal menjadi hernia inguinalis (Agustina, 2014).

Hernia inguinalis lateralis inguinalis lateralis. Sementara itu, 6 responden $(60 \%)$ responden yang didiagnosa hernia inguinalis medialis memiliki berat badan overweightobesitas sedangkan 4 responden lainnya (40\%) yang didiagnosa hernia inguinalis medialis memiliki berat badan overweight-obesitas. Hasil uji statistik diperoleh nilai $p$-value 0,013 . Hal tersebut menunjukkan terdapat hubungan yang bermakna antara indeks massa tubuh dengan jenis hernia inguinalis.

menonjol dari perut di lateral pembuluh epigastrika inferior, dan disebut indirek karena keluar melalui dua pintu dan saluran yaitu anulus dan kanalis inguinalis, tidak langsung menembus dinding abdomen. Penyebab terjadinya hernia inguinalis lateralis ini karena anomali kongenital atau karna sebab yang didapat. Keluhan pada penderita hernia inguinalis lateralis yaitu berupa benjolan di lipat paha yang timbul pada saat mengejan, batuk, atau mengangkat beban berat dan menghilang pada saat istirahat baring (Rawis, dkk., 2015).

Hernia inguinalis medialis hampir selalu disebabkan oleh peningkatan tekanan intraabdomen. Hernia ini menonjol langsung ke depan melalui trigonum Hasselbach, daerah yang dibatasi oleh ligamentum inguinale dibagian inferior pembuluh epigastrika inferior di bagian lateral dan tepi otot rektus dibagian medial. Hernia 
ini umumnya terjadi bilateral, khususnya pada lelaki tua. Hernia inguinalis medialis hampir tidak pernah mengalami inkarserasi dan strangulasi (Sjamsuhidajat, 2017).

Pada orang yang mempunyai

berat badan overweight-obesitas atau obesitas memang menjadi banyak faktor resiko terjadinya penyakit-penyakit, termasuk ada diadalamnya hernia inguinalis karena tekanan intra abdomen yang tinggi. Banyaknya lemak preperitoneal akan mendesak dinding abdomen dan menimbulkan lokus minoris atau kelemahankelemahan otot serta terjadi relaksasi dari anulus. Bila lemak menginfiltrasi ke omentum dan mesenterium akan mengurangi volume rongga abdomen sehingga terjadi peningkatan tekanan intraabdomen yang akan mendorong organ interna menjadi hernia inguinalis (Ruhl dan Everhart, 2007).

Penelitian ini sejalan dengan penelitian yang dilakukan oleh Agustina (2014) yang menyatakan bahwasannya ada hubungan antara obesitas dengan kejadian hernia inguinalis ( $p$ value $=0,002, O R=0,292$, $\mathrm{Cl}=0,131-0,674)$. Jenis kelamin merupakan variabel perancu dalam hubungan antara obesitas dengan kejadian hernia inguinalis ( $\mathrm{p}$ value 0,051). Akan tetapi, teori ini dibantah oleh penelitian yang dilakukan oleh Salampessy (2019). Berdasarkan penelitiannya, hasil uji statistik Chi-Square didapatkan nilai probabilitas $=0.988(\mathrm{p}>\mathrm{a}=0.05)$ dengan nilai $=0,325$. Hasil analisis secara statistik ini menunjukan bahwa tidak terdapat hubungan yang bermakna antara indeks massa tubuh dengan kejadian Hernia Inguinalis Di RSUD Dr. M. Haulussy Ambon. Sejalan dengan penelitian yang dilakukan oleh Dario dkk pada tahun 2016 juga menyatakan bahwa hubungan indeks massa tubuh dan hernia inguinalis tidak jelas (unclear) (Dario, 2016). Pada penelitian yang dilakukan oleh Ghayth, Waseem Kamel dkk pada tahun 2016, dalam analisisnya menggunakan model multiple logistic regression menyatakan bahwa indeks massa tubuh tidak secara langsung atau secara statistik memiliki hubungan sebagai faktor resiko hernia inguinalis. Dari hasil penelitian menyatakan tidak ada hubungan yang bermakna antara indeks massa tubuh dengan kejadian hernia inguinalis, hal ini dimungkinkan karena indeks massa tubuh hanya berkaitan dengan otot dinding abdomen baik yang mengalami kelemahan maupun tidak. Dinding abdomen tidak bisa dikatakan sebagai faktor tunggal dalam proses terjadinya hernia karena kekuatan dinding abdomen dipengaruhi juga oleh tekanan intra-abdomen. Literatur sebelumnya menyakini bahwa tidak seimbangnya tekanan intra-abdomen dan kekuatan dinding abdomen akan menyebabkan hernia kongenital maupun yang didapat dan obesitas merupakan titik acuan karena obesitas sendiri akan meningkatkan tekanan intra-abdomen yang mempengaruhi resisten dari dinding abdomen, sehingga para peneliti sebelumnya menyakini indeks massa tubuh karena penilaian obesitas dapat dilihat dari indeks massa tubuh (Ghayth, 2016).

Hasil yang berbeda didapatkan oleh Rosemar dkk (2008), dalam jurnalnya Rosemar dkk tidak mendapatkan bukti ilmiah pasti mengenai hubungan antara indeks massa tubuh dan kejadian hernia. Selain itu, dalam penelitiannya juga didapatkan bahwa tekanan intra-abdomen lebih meningkat pada usia muda dan pada lansia datanya kurang jelas. Rosemar dkk, juga menemukan bahwa berat badan lebih 
(overweight) dan obesitas dapat menjadi faktor pelindung, hal ini dikaitkan dengan aktivitas, aktivitas sendiri juga merupakan salah satu faktor yang meningkatkan tekanan intra-abdomen. Hal ini juga didukung oleh penelitian yang dilakukan oleh Cobb dkk yang meneliti tentang tekanan intraabdomen, dalam jurnalnya Cobb dkk membuktikan bahwa aktivitas sehari-hari dapat meningkatkan tekanan intra-abdomen, dimana berdiri, menekuk lutut, melompat, dan valsava saat berdiri mempunyai hubungan bermakna dalam peningkatan intra-abdomen (Cobb, 2005). Rosemar dkk menyakini orang yang overweight dan obesitas kurang beraktivitas sehingga resiko terjadinya berkurang, walaupun dalam penelitianya tidak diteliti sampai hal tersebut, dalam jurnalnya juga diberi dua teori mengenai hal tersebut, teori yang pertama ruang intra-abdomen pada overweight dan obesitas terdiri dari lemak dan hal tersebut berhubungan dengan omentum dan mesenterium, jika kedua hal tersebut "tumpul" dan pendek maka akan mencegah potensi terjadinya protrusi hernia. Teori yang kedua jika lemak menyebabkan tebalnya dinding abdomen maka akan mencegah terjadinya hernia, walaupun pada penelitiannya teori tersebut tidak dibuktikan (Cobb 2005; Rosemar, 2008).

Pada penelitian yang dilakukan Ghayth, Waseem Kamel dkk pada Tahun 2016, menyatakan untuk terjadinya hernia inguinalis karena adanya gangguan metabolisme kolagen atau abnormalitas dari kolagen yang akan menyebabkan patologi pada jaringan ikat dan menyebabkan kelemahan pada struktur penyokong. teori ini didukung kerusakan atau lemahnya jaringan ikat, keduanya memegang peranan penting dalam terjadinya hernia inguinalis (Ghayth, 2016).

Hal ini didukung pada penelitian yang dilakukan oleh Goede pada 2015 yang menyatakan bahwa pada hernia inguinalis terjadi peningkatan metalloprotease 2 dan 9 dan pada jaringan terjadi penuruan dari inhibitor dari metalloprotease 1 dan

2 yang berperan dalam degenerasi kolagen (Goede, 2015). Abnormal dari metabolisme kolagen dapat ditemukan pula perokok, karena pada perokok terjadi penurunan dari deposisi kolagen hal ini dikemukakan oleh Sorrensen, Lars Tue dkk (Sorensen, 2002). Berdasarkan uraian diatas maka dapat lihat gangguan dari metabolism kolagen sangat jelas berperan dalam menjadi penyebab terjadinya hernia inguinalis.

Pada penelitian yang dilakukan oleh Balamaddaiah, $\mathrm{G}$ dkk pada Tahun 2016 mengenai faktor resiko hernia inguinalis, ditemukan bahwa kebanyakan pasien hernia inguinalis adalah laki -laki daripada perempuan, hal ini dimungkinkan karena laki -laki lebih sering bekerja daripada perempuan (Balamaddaiah, 2016). Selain itu berdasarkan anatomi terdapat perbedaan antara kanalis inguinalis pada laki-laki dan perempuan, dimana pada laki-laki diameter kanalis inguinalis lebih besar. Dari uraian tersebut dapat dilihat bahwa indeks massa tubuh bukan faktor resiko yang berpengaruh secara spesifik terhadap kejadian hernia inguinalis.

\section{KESIMPULAN}

1. Diketahui karakteristik indeks massa tubuh di RS Pertamina Bintang Amin Kota Bandar Lampung tahun 2020 didapatkan 24 responden $(24,5 \%)$ memiliki 
berat badan normal dan 74 responden lainnya $(75,5 \%)$ memiliki berat badan overweight-obesitas.

2. Diketahui karakteristik kejadian hernia inguinalis di RS Pertamina Bintang Amin Kota Bandar Lampung tahun 2020 didapatkan 88 responden $(89,80 \%)$ didiagnosa hernia inguinalis lateralis dan 10 responden $(10,20 \%)$ responden didiagnosa hernia inguinalis medialis.

3. Diketahui hasil uji statistik diperoleh nilai $p$-value 0,013 dimana kurang dari nilai kemaknaan yaitu $5 \%(0,05)$. Hal tersebut menunjukkan terdapat hubungan yang bermakna antara indeks massa tubuh dengan jenis hernia inguinalis.

\section{DAFTAR PUSTAKA}

Agustina, V. A. (2014). Hubungan Antara Obesitas Dengan Kejadian Hernia Inguinalis. Unnes Journal of Public Health, 3(3).

Amanullah, Risfal Laksana. (2016). Hubungan Usia, Obesitas Dan Aktivitas Fisik Dengan Kejadian Hernia Inguinalis Di Rsud Tugurejo Semarang. Undergraduate Thesis. Unimus.

Balamaddaiah, G et al. (2016). Prevalence and Risk Factor of Inguinal Hernia: A Study In A Semu-Urban Area In Rayalaseema, Andhra Pradesh, India. 3(3): 13101313.

Cobb, W., Kerchner, W. and Heniford, T. (2005). The Argument of Light Weight Polypropylene Mesh in Hernia Repair. Surgical Innovation, 12, 63-69. DOI: https: / / doi.org/10.1177/155 335060501200109

Dario, B., Patricia, L., Andrea Luigi Ambrosoli,

Gianluca
Cappelleri, Gloria Mr Saccani Jotti, Tiziana Meschi, Guido Fanelli, And Massimo Allegri. (2016). Effect of Preoperative Inflammatory Status And Comorbidities On Pain Resolution And Persistent Postsurgical Pain After Inguinal Hernia Repair. Mediators of Inflammation. Doi:10.1155/2016/5830347

Ghayth, Waseem Kamel, Gorial, F Isho. (2016). Assessment of Joint Hypermobility In Adult Patient With Inguinal Hernia: An Analytical Cross Sectional Study From Iraq. 6(18): 16-19.

Goede, Barry De, et al. (2015). Risk Factor for Inguinal Hernia in Middle-Age And Elderly: Results From the Rotterdam Study. Rotterdam. 157(3): 540-545.

Gunawan, I. M. K., Saraswati, P. A. I., \& Putra, P. M. G. A. (2020). Relationship Between Obesity With Risk Of Obstruction In Lateral Inguinal Hernia. International Journal Of Health \& Medical Sciences. 3(1): 35-41. https: / /Doi.Org/10.31295/ljh ms.V3n1.124

Kato, J.M., luamoto, L.R., Suguita, F.Y., Essu, F.F., Meyer, A., Andraus, W. (2017). Impact Of Obesity And Surgical Skills In Laparoscopic

Totally Extraperitoneal

Hernioplasty. Abcd Arq Bras Cir Dig. 30(3):169-172 Doi: $/ 10.1590 / 0102-$

6720201700030002

Kementerian Kesehatan Republik Indonesia. (2015). Profil Data Kesehatan Indonesia Tahun 2014. Jakarta: Kementerian Kesehatan Republik Indonesia.

Lavelle, M Et Al. (2002). Surgery 1. 2rd Rev. London: Churchill Livingstone. 
Park, C.Y.; Kim, J.C.; Kim, D.Y.; Kim, S.K. 2011. Inguinal Hernia Repair In Overweight And Obese Patient. J Korean Surg Soc. 81(3): 205 - 10 P.

Pluta, R.M.; Burke, A.E.; Golub, R.M. (2011). Abdominal Hernia. Jama. 305: 20 P.

Rawis, C.G., Limpeleh, H.P., Wowiling, P.A.V. 2015. Pola Hernia Inguinalis Lateralis Di RSUP Prof. Dr. R. D. Kandou Manado Periode Agustus 2012 - Juli 2014. Jurnal e-Clinic (eCl). 3(2): 695-699.

Rezky N. P. Salampessy, Achmad Tuahuns, Johan B. Bension. (2019). Hubungan Antara Indeks Massa Tubuh Dengan Kejadian Hernia Inguinalis Di Rsud Dr. M. Haulussy Ambon. Pameri. Issn 2686-5165 (Online). Vol. 1; No. 1. April.

Rosemar, Anders et al. (2008). Body Mass Index and Groin Hernia: A 34-Year Follow-Up Study In Swedish Men. Lippincott Williams \& Wilkins. 247(6): 1064-1068.
Rossetto, L.A Et Al. (2010). Factor Associated With Hernia And Nulge Formation At The Donor Site of The Pedicled Tram Flap. Eur J Past Surg. 33(4): $203-8$ P.

Ruhl CE, Everhart JE. (2007). Risk factors for inguinal hernia among adults in the US population. American Journal of 165(10):1154-61.

Epidemiology.

Siti Aisyah, Andri Dwi Hernawan, Sutriswanto. (2016). Faktor Yang Berhubungan Dengan Kejadian Penyakit Hernia Inguinal Pada Laki-Laki Di Rumah Sakit Umum Dr. Soedarso Pontianak. Jumantik. 3(2): 1-7.

Sjamsuhidajat, D. (2017). Buku Ajar Ilmu Bedah (Edisi IV Ed.). Jakarta: Penerbit Buku Kedokteran EGC.

Sorensen, Lars Tue et al. (2002). Smoking Is A Risk Factor For Recurrence of Groin Hernia. World of Journal Of Surgery. 26: 397-400. 